\title{
MHD boundary layer flow and heat transfer characteristics of a nanofluid over a stretching sheet
}

\author{
M. Ferdows \\ Department of Applied Mathematics, \\ University of Dhaka, Bangladesh \\ email: ferdows@du.ac.bd \\ Md. Mahmud Alam \\ Mathematics Discipline, \\ Khulna University, Bangladesh \\ email: alam_mahmud2000@yahoo.com
}

\section{Md. Shakhaoath Khan}

Discipline of Chemical Engineering,

University of Newcastle, Australia email: mdshakhaoath.khan@uon.edu.au

\author{
A. A. Afify \\ Department of Mathematics, \\ Deanship of Educational Services, \\ Qassim University, Saudi Arabia \\ email: afify60@hotmail.com
}

\begin{abstract}
The study of radiative heat transfer in a nanofluid with the influence of magnetic field over a stretching surface is investigated numerically. Physical mechanisms responsible for magnetic parameter, radiation parameter between the nanoparticles and the base fluid, such as Brownian motion and thermophoresis, are accounted for in the model. The parameters for Prandtl number $P r$, Eckert number $E c$, Lewis number $L e$, stretching parameter $b / a$ and constant parameter $m$ are examined. The governing partial differential equations were converted into nonlinear ordinary differential equations by using a suitable similarity transformation, which are solved numerically using the Nactsheim-Swigert shooting technique together with Runge-Kutta six order iteration scheme. The accuracy of the numerical method is tested by performing various comparisons with previously published work and the results are found to be in excellent agreement. Numerical results for velocity, temperature
\end{abstract}

2010 Mathematics Subject Classification: $76 \mathrm{Mxx}$

Key words and phrases: boundary layer, nanofluid, magnetic field, thermal radiation, Brownian motion, thermophoresis 
and concentration distributions as well as skin-friction coefficient, Nusselt number and Sherwood number are discussed at the sheet for various values of physical parameters.

\section{Introduction}

Nanofluid technology has been receiving a lot of attention as a research topic and takes important part for further development of higher performance due to effective applications in the field of electronics engineering, transportation, biomedical research etc. Choi [1] created 'Nanofluids' by suspending nanometresized metallic particles in common fluids and reported their highly enhanced thermal properties.

Nanofluids have novel properties that make them potentially useful in many applications in heat transfer, including microelectronics, fuel cells, pharmaceutical processes, and hybrid-powered engines. Nanoparticles are of great scientific interest as they are effectively a bridge between bulk materials and atomic or molecular structures. In the past decades, heat transfer enhancement technology has been developed and widely applied to heat exchanger applications; for example, refrigeration, automotives, process industry, chemical industry, etc. There are numerous biomedical applications that involve nanofluids such as magnetic cell separation, drug delivery, cancer therapeutics, cry preservation, Nan cryosurgery. The random motion of nanoparticles within the base fluid is called Brownian motion, and results from continuous collisions between the nanoparticles and the molecules of the base fluid. The nanoparticle concentration, base fluid, and particle size appear to be the most influential parameters for improving the heat transfer efficiency of nanofluid. Thermophoresis is important when the particle sizes are small and the temperature gradients are large.

Thermal radiation is important in some applications because of the manner in which radiant emission depends on temperature and nanoparticle volume fraction. Rad and Aghanajafi [2] studied the thermal analysis of single phase laminar flow nanofluid cooled rectangular microchannel heat sink (MCHS) subject to the uniform wall temperature condition. Afify et al. [3] studied the steady two-dimensional boundary layer flow past a wedge immersed in nanofluids under the effects of thermal radiation and non-uniform heat source (or sink).

The study of the magnetohydrodynamic (MHD) flow for electrically conducting fluid past a heated surface has attracted many researchers in view of its important applications in many engineering problems such as plasma 
studies, petroleum industries, magnetohydrodynamic power generators, cooling of nuclear reactors, the boundary layer control in aerodynamics, and crystal growth. The effect of the magnetic field over a stretching surface with or without heat and mass transfer was investigated by Vajravelu and Hadjincolaou [4], Pop and Na [5], Takhar et al. [6], Chamkha [7], Singh et al. [8], Ferdows et al. [9] and Afify [10, 11]. Recently, Turkyilmazoglu [12] investigated the magnetohydrodynamic slip flow of an electrically conducting, viscoelastic fluid past a stretching surface. All these studies were concerned the electrically conducting fluid with a low thermal conductivity. This, in turn, limits the enhancement of heat transfer in the enclosure particularly in the presence of the magnetic field. Nanofluids with enhanced thermal characteristics have widely been examined to improve the heat transfer performance of many engineering applications [1]. The characteristic feature of nanofluids is thermal conductivity enhancement, a phenomenon observed by Masuda et al. [13]. This phenomenon suggests the possibility of using nanofluids in advanced nuclear systems (Buongiorno and $\mathrm{Hu}$ [14]). Yu et al. [15] and Murshed et al. [16], provide a detailed literature review of nanofluids including synthesis, potential applications, experimental and analytical analysis of effective thermal conductivity, effective thermal diffusivity, and convective heat transfer.

The research on nanofluids is gaining a lot of attention in recent few years. The effect of various parameters on nanofluid thermal conductivity has been obtained by Jang and Choi [17]. The convective heat transfer in a nanofluid past a vertical plate using a model in which Brownian motion and Thermophoresis are accounted with the simplest possible boundary conditions have discussed by Kuznestov and Neild [18, 19], they have also studied the problem of natural convection past a vertical plate analytically in a porous medium saturated by a nanofluid. Khan and Pop [20] have investigated the problem of laminar fluid flow over the stretching surface in a nanofluid and they investigated it numerically.

Very recently, an analytical solution for boundary layer flow of a nanofluid past a stretching sheet was examined by Hassani et al. [21]. They compared the result with Khan and Pop [20]. Avramenko et al. [22] analyzed a self-similar analysis of fluid flow and boundary layer heat-mass transfer of nanofluids. Boundary layer flow of a nanofluid over a moving surface in a flowing fluid has been studied by Bachok et al. [23]. The problem of steady boundary layer shear flow over a stretching/shrinking sheet in a nanofluid was investigated by Yacob et al. [24]. They found that the heat transfer rate at the surface increases with increasing nanoparticles volume fraction while it decrease with convective parameter. Ferdows and Hamad [25, 26] studied a similarity so- 
lution of boundary layer stagnation-point of nanofluid flow; and investigate viscous flow of heat transfer of nanofluid over nonlinearly stretching sheet.

On the other hand, the study of Magnetohydrodynamics (MHD) boundary layer flow of a nanofluid over a stretching surface has become several industrial, scientific and engineering applications. Engineers employ MHD principle in the design of heat exchangers, pumps and flow matters, in space vehicle propulsion, thermal protection, controlling the rate of cooling etc. A number of technical processes concerning polymers involve the cooling of continuous strips or filaments by drawing them through a quiescent fluid. Further glass blowing, manufacture of plastic and rubber sheet, continuous casting of metals and spinning of flows involve the flow due to a stretching surface. MHD natural convection nanofluid flow over a linearly stretching sheet was analyzed by Hamad [27]. Aminossadati et al. [28] studied the heat transfer performance of water- $\mathrm{Al}_{2} \mathrm{O}_{3}$ nanofluid in a horizontal microchannel that is under the influence of a transverse magnetic field. Recently, Hamad and Pop [29] studied the unsteady magnetohydrodynamic flow of a nanofluid past an oscillatory moving vertical permeable semi-infinite flat plate with constant heat source in a rotating frame of reference.

The objective of the present study is to investigate the steady of MHD boundary layer flow, heat transfer and concentration distribution over a stretching surface in a nanofluid in the presence of thermal radiation with Brownian motion and thermophoresis. By using similarity transformations, the set of governing equations and the boundary conditions are reduced to nonlinear coupled ordinary differential equations with appropriate boundary conditions. Furthermore, the similarity equations are solved numerically by using the Nactsheim-Swigert shooting technique together with Runge-Kutta six order iteration schemes. The obtained results are shown graphically, and the physical aspects of the problem are discussed. Also, the skin-friction coefficient, Nusselt number and Sherwood number are discussed numerically for different variations of the physical parameters included in the analysis.

\section{Mathematical formulation}

Consider steady two-dimensional boundary layer flow of a nanofluid past a stretching sheet with a linear velocity variation with the distance $x$ i.e. $\mathfrak{u}_{w}=a x$ where $\mathrm{a}$ is a constant and $\mathrm{x}$ is the coordinate measured along the stretching surface, as shown in figure 1. A steady uniform stress leading to equal and opposite forces is applied along the $x$-axis so that the sheet is stretched keeping 


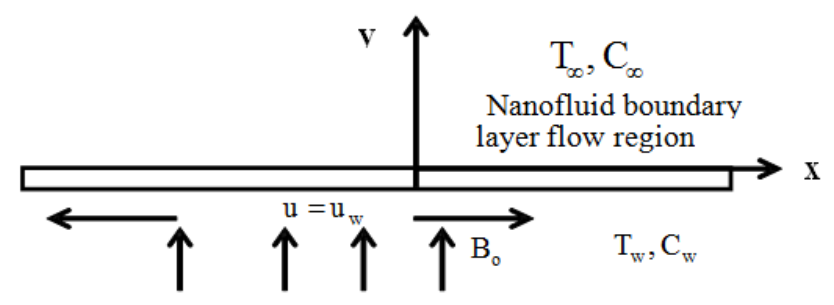

Figure 1: A sketch of the physical problem

the origin fixed. The flow is considered to be laminar, Newtonian, incompressible and electrically conducting fluid. The impressed electrical field is assumed to be zero and both the induced magnetic and electric fields of the flow are negligible in comparison with the applied magnetic field which corresponds to very small magnetic Reynolds number. The temperature and the concentration of the ambient fluid are $T_{\infty}$ and $C_{\infty}$, and those at the stretching surface are $T_{w}$ and $C_{w}$ respectively. The velocity of the plate (uniform velocity) considered as $\mathrm{U}$ and $\mathrm{q}_{\mathrm{r}}$ is radiative heat flux in the $\mathrm{y}$-direction. A magnetic field of uniform strength $B_{0}$ is applied in the $y$-direction normal to the plate surface. Also $a$ and $b$ are the linear stretching constant, $l$ is the characteristics length and $A_{1}, A_{2}$ are the constants whose values depend on the properties of the fluid. Under these assumptions, the boundary layer form of the governing equations is given by Kuznetsov and Nield [18] and Nield and Kuznetsov [19]:

$$
\begin{gathered}
\frac{\partial u}{\partial x}+\frac{\partial v}{\partial y}=0 \\
u \frac{\partial u}{\partial x}+v \frac{\partial u}{\partial y}=u \frac{d u}{d x}+v \frac{\partial^{2} u}{\partial y^{2}}+\frac{\sigma B_{0}^{2}}{\rho}(\mathrm{U}-u) \\
u \frac{\partial T}{\partial x}+v \frac{\partial T}{\partial y}=\alpha \frac{\partial^{2} T}{\partial y^{2}}-\frac{\alpha}{\kappa} \frac{\partial q_{r}}{\partial y}+\frac{\alpha}{c_{p}}\left(\frac{\partial u}{\partial y}\right)^{2}+\tau\left(D_{B} \frac{\partial T}{\partial y} \frac{\partial C}{\partial y}+\frac{D_{T}}{T_{\infty}}\left(\frac{\partial T}{\partial y}\right)^{2}\right) \\
u \frac{\partial C}{\partial x}+v \frac{\partial C}{\partial y}=D_{B} \frac{\partial^{2} C}{\partial y^{2}}+\frac{D_{T}}{T_{\infty}}\left(\frac{\partial^{2} T}{\partial y^{2}}\right)
\end{gathered}
$$

The boundary conditions for this problem can be written as

$$
\begin{gathered}
u=a x, v=0, T=T_{w}=T_{\infty}+A_{1}\left(\frac{x}{l}\right)^{m}, C=C_{w}=C_{\infty}+A_{2}\left(\frac{x}{l}\right)^{m} \text { at } y=0 \\
u=u=b x, \quad T=T_{\infty}, \quad C=C_{\infty} \text { as } y \rightarrow \infty
\end{gathered}
$$


where, $\alpha$ is the thermal diffusivity, $k$ is the thermal conductivity, $D_{B}$ is the Brownian diffusion coefficient and $\mathrm{D}_{\mathrm{T}}$ is the thermophoresis diffusion coefficient. The Rosseland approximation [30] has been considered for radiative heat flux which leads to:

$$
q_{r}=-\frac{4 \sigma}{3 \kappa^{*}} \frac{\partial T^{4}}{\partial y}
$$

where, $\sigma$ is the Stefan-Boltzmann constant and $k^{*}$ is the mean absorption coefficient. The temperature difference with in the flow is sufficiently small such that $\mathrm{T}^{4}$ may be expressed as a linear function of the temperature, then the Taylors series for $\mathrm{T}^{4}$ about $\mathrm{T}_{\infty}$ after neglecting higher order terms, $\mathrm{T}^{4}=$ $4 \mathrm{~T}_{\infty}^{3}-3 \mathrm{~T}_{\infty}^{4}$.

In order to attains a similarity solution to equations (1) to (4) with the boundary conditions (5) the following dimensionless variables are used,

$$
\begin{gathered}
\eta=y \sqrt{\frac{a}{v}}, \psi=x \sqrt{a v} f(\eta), \theta(\eta)=\frac{T-T_{\infty}}{T_{w}-T_{\infty}}, \varphi(\eta)=\frac{C-C_{\infty}}{C_{w}-C_{\infty}} \\
\text { and } u=\frac{\partial \psi}{\partial y}, v=-\frac{\partial \psi}{\partial x}
\end{gathered}
$$

From the above transformations the non dimensional, nonlinear, coupled ordinary differential equations are obtained as:

$$
\begin{gathered}
f^{\prime \prime \prime}+f f^{\prime \prime}-f^{\prime 2}+M\left(\frac{\mathrm{b}}{\mathrm{a}}-f^{\prime}\right)+\frac{\mathrm{b}^{2}}{\mathrm{a}^{2}}=0 \\
(1+R) \theta^{\prime \prime}+E c \operatorname{Pr} f^{\prime \prime 2}+\operatorname{Prf} \theta^{\prime}-m \operatorname{Pr} f^{\prime} \theta+\operatorname{Pr} N b \theta^{\prime} \varphi^{\prime}+\operatorname{Pr} N t \theta^{\prime 2}=0 \\
\varphi^{\prime \prime}+\operatorname{Lef} \varphi^{\prime}+\frac{N t}{N b} \theta^{\prime \prime}-m L e f^{\prime} \varphi=0
\end{gathered}
$$

and the corresponding boundary conditions,

$$
\begin{gathered}
f=0, \quad f^{\prime}=1, \quad \theta=1, \quad \varphi=1 \text { at } \eta=0 \\
f^{\prime}=\frac{b}{a}, \quad \theta=0, \quad \varphi=0 \text { as } \eta \rightarrow \infty
\end{gathered}
$$

where the notation primes denote differentiation with respect to $\eta$ and the parameters are defined as Magnetic parameter $M=\frac{\sigma \mathrm{B}_{0}^{2}}{\rho \mathrm{a}}$, Radiation parameter $R=\frac{16 \sigma \mathrm{T}_{\infty}^{3}}{3 \mathrm{~K}^{*}}$, Prandtl number $\operatorname{Pr}=\frac{v}{\alpha}$, Eckert number $E c=\frac{\mathrm{u}_{w}^{2}}{\mathrm{c}_{\mathrm{p}}\left(\mathrm{T}_{w}-\mathrm{T}_{\infty}\right)}$, Lewis number $L e=\frac{v}{D_{\mathrm{B}}}$, Brownian parameter $N b=\frac{(\rho c)_{\mathrm{p}} \mathrm{D}_{\mathrm{B}}\left(\varphi_{w}-\varphi_{\infty}\right)}{v(\rho c)_{\mathrm{f}}}$, Thermophoresis 
parameter $N t=\frac{(\rho c)_{\mathrm{p}} \mathrm{D}_{\mathrm{T}}\left(\mathrm{T}_{w}-\mathrm{T}_{\infty}\right)}{v \mathrm{~T}_{\infty}(\rho \mathrm{c})_{\mathrm{f}}}$, stretching parameter $b / a$ and constant parameter $m$. The physical quantities of the skin-friction coefficient, the reduced Nusselt number and reduced Sherwood number are calculated respectively by the following equations,

$$
\begin{gathered}
C_{f} R e_{\mathrm{x}}^{-1 / 2}=-f^{\prime \prime}(0) \\
N u R e_{\mathrm{x}}^{-1 / 2}=-(1+R) \theta^{\prime}(0) \\
S h R e_{\mathrm{x}}^{-1 / 2}=-\varphi^{\prime}(0)
\end{gathered}
$$

where $R e_{x}=\frac{\chi_{\mathfrak{u}_{w}}(\mathrm{x})}{v}$ is the local Reynolds number.

\section{Numerical technique}

The non dimensional, nonlinear, coupled ordinary differential equations (8) to (10) with boundary condition (11) are solved numerically using standard initially value solver the shooting method. For the purpose of this method, the Nactsheim-Swigert shooting iteration technique [31] together with RungeKutta six order iteration scheme is taken and determines the temperature and concentration as a function of the coordinate $\eta$. Extension of the iteration shell to above equation system of differential equation (11) is straight forward, there are three asymptotic boundary condition and hence three unknown surface conditions $f^{\prime \prime}(0), \theta^{\prime}(0)$ and $\varphi^{\prime}(0)$.

\section{Results and discussion}

The heat and mass transfer problem associated with laminar flow of the nanofluids over a stretching surface has been studied. In order to investigate the physical representation of the problem, the numerical values of velocity $f^{\prime}$, temperature $\theta$ and species concentration $\varphi$ with the boundary layer have been computed for different parameters as the Magnetic parameter $M$, the Radiation parameter $R$, the Prandtl number $P r$, the Eckert number $E c$, the Lewis number $L e$, the Brownian motion parameter $N b$, the Thermophoresis parameter $N t$, the stretching parameter $b / a$ and constant parameter $m$ respectively.

Comparison: In order to assess the accuracy of the numerical results the present results are compared with the solution of Khan and Pop [20] and the values of the Magnetic parameter $M$, the Radiation parameter $R$, the Eckert number $E c$, the stretching parameter $b / a$, and constant parameter $m$ are considered zero (see figures $2-5$ and table 1 ). 
Table 1: Comparison of results for the reduced Nusselt number when $M=0$, $R=0, E c=0, b / a=0, P r=L e=10$, and $m=0$

\begin{tabular}{c|c|c}
\hline Parameter $N b=N b=0$ & Present results & Khan and Pop $[20]$ \\
\hline 0.1 & 0.9524 & 0.9524 \\
0.2 & 0.3653 & 0.3654 \\
0.3 & 0.1351 & 0.1355 \\
0.4 & 0.0490 & 0.0495 \\
0.5 & 0.0178 & 0.0179 \\
\hline
\end{tabular}

From table 1 it is observed that, with increasing the Brownian motion parameter and thermophoresis parameter Nusselt number decreases. Therefore the comparison shows a good agreement.

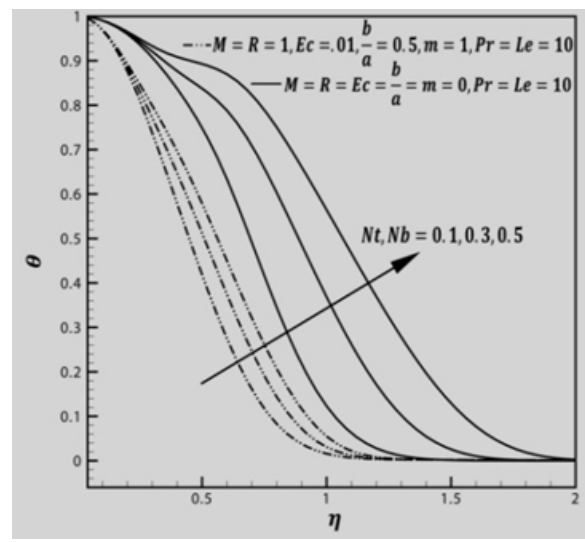

Figure 2: Effect of $N t$ and $N b$ on temperature profiles

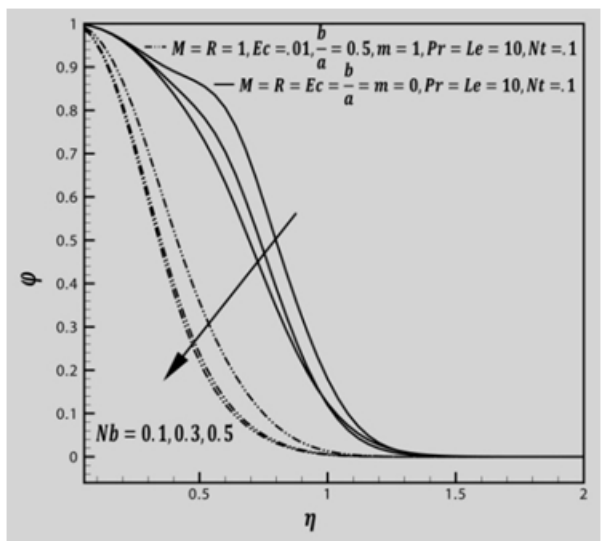

Figure 3: Effect of $\mathrm{Nb}$ on concentration profiles

Figure 2 represents the dimensionless temperature distribution $\theta(\eta)$ for different values of $N b$ where $\operatorname{Pr}=L e=10, N t=0.1, M=1.0, R=1.0, b / a=0.5$, $E c=0.01$ and $m=1.0$. For comparison, the values of Magnetic parameter $M$, the Radiation parameter $R$, the Eckert number $E c$, the stretching parameter $b / a$ and constant parameter $m$ are considered zero. Then for above cases it is observed that, temperature increases as the thermophoresis parameter $N t$ and the Brownian motion parameter $N b$ increases. The qualitative agreement between these two results is good.

Figure 3 displays the dimensionless concentration distribution $\varphi(\eta)$ for dif- 


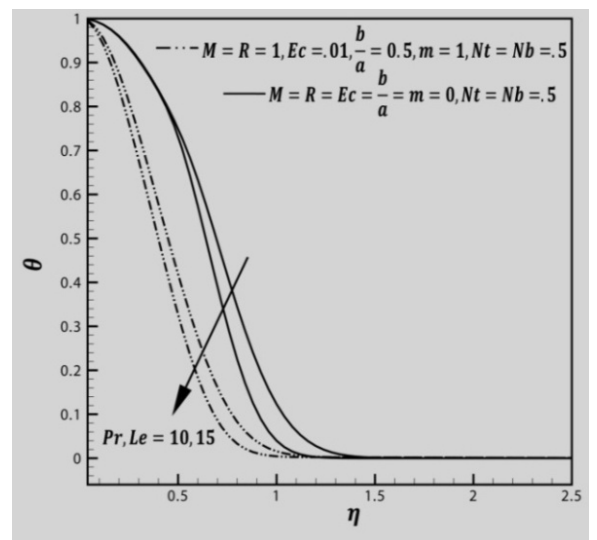

Figure 4: Effect of $\operatorname{Pr}$ and Le on temperature profiles

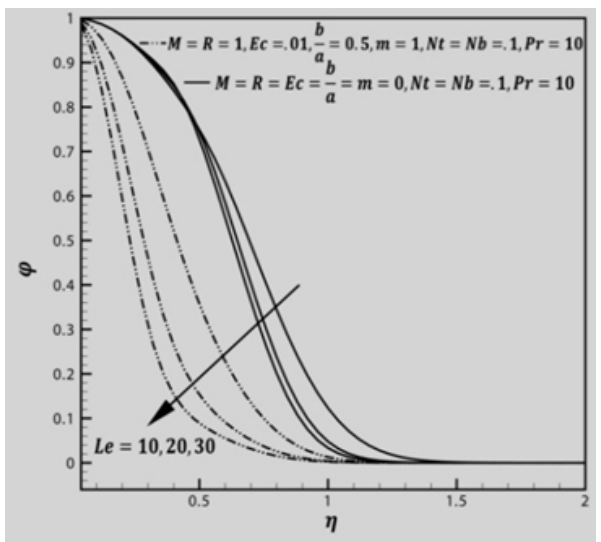

Figure 5: Effect of Le on concentration profiles

ferent values of $N b$ where $\operatorname{Pr}=L e=10, N t=0.1, M=1.0, R=1.0, b / a=$ $0.5, E c=0.01$ and $m=1.0$. For comparison, the values of Magnetic parameter $M$, the Radiation parameter $R$, the Eckert number $E c$, the stretching parameter $b / a$ and constant parameter $m$ are considered zero. Then it is examined for both cases, concentration decreases as the Brownian motion parameter increases. The qualitative agreement between these two results is good.

Figure 4 shows the dimensionless temperature distribution $\theta(\eta)$ for different values of $\operatorname{Pr}$ and $L e$ where $N t=N b=0.5, M=1.0, R=1.0, b / a=0.5, E c=$ 0.01 and $m=1.0$. For comparison, the values of Magnetic parameter $M$, the Radiation parameter $R$, the Eckert number $E c$, the stretching parameter $b / a$ and constant parameter $m$ are considered zero. Then for both cases it is noted that, temperature decreases as increases. The qualitative agreement between these two results is good.

Figure 5 exhibits the dimensionless concentration distribution $\varphi(\eta)$ for different values of $L e$ where $N t=N b=0.1, \operatorname{Pr}=10, M=1.0, R=1.0, b / a=$ $0.5, E c=0.01$ and $m=1.0$. For the comparison, the values of Magnetic parameter $M$, Radiation parameter $R$, Eckert number $E c$, stretching parameter $b / a$ and constant parameter $m$ are considered zero. Then it is detected for both cases, concentration profiles decreases as Le increases. The qualitative agreement between these two results is good.

Also an effect on thermal boundary layer thickness and concentration boundary layer thickness have been found in figures 2-5, when Magnetic parameter $M$, Radiation parameter $R$, the Eckert number $E c$, stretching parameter $b / a$ and constant parameter $m$ are introduced. 


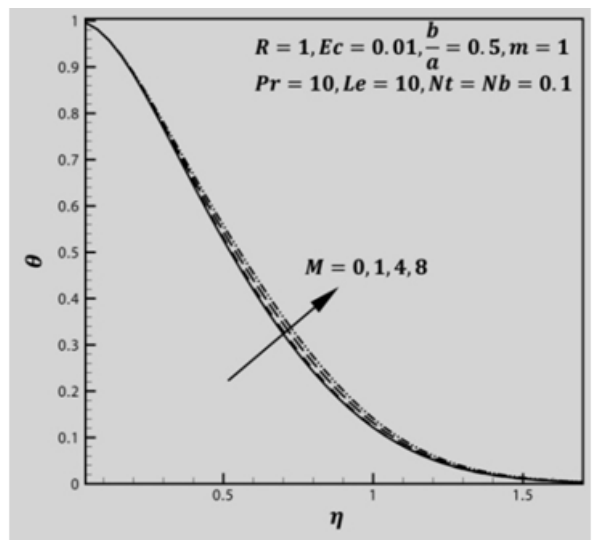

Figure 6: Effect of $M$ on temperature profiles

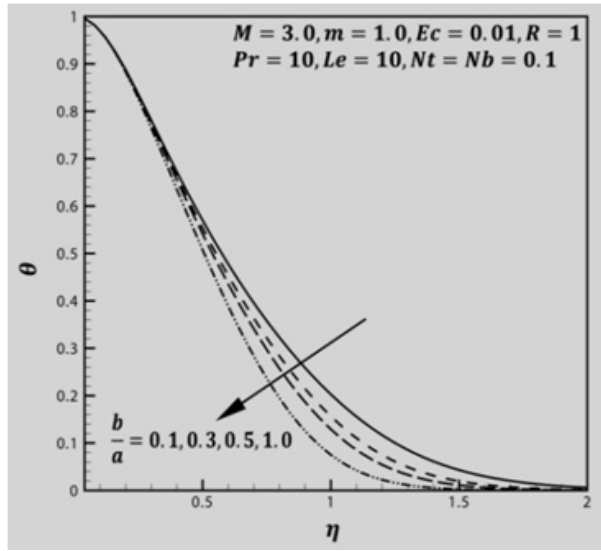

Figure 8: Effect of $b / a$ on temperature profiles

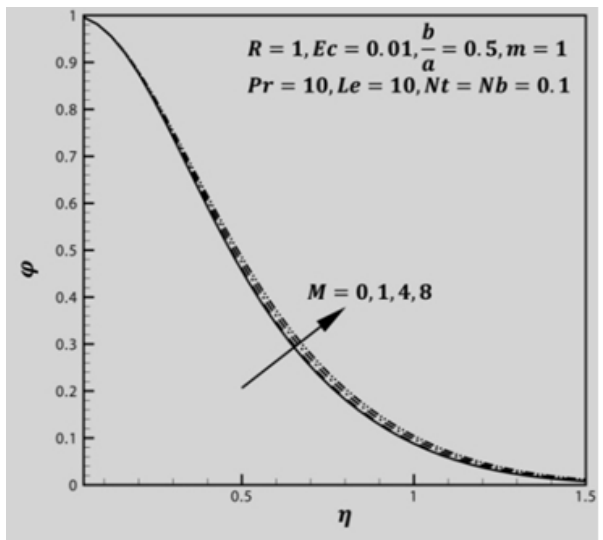

Figure 7: Effect of $M$ on concentration profiles

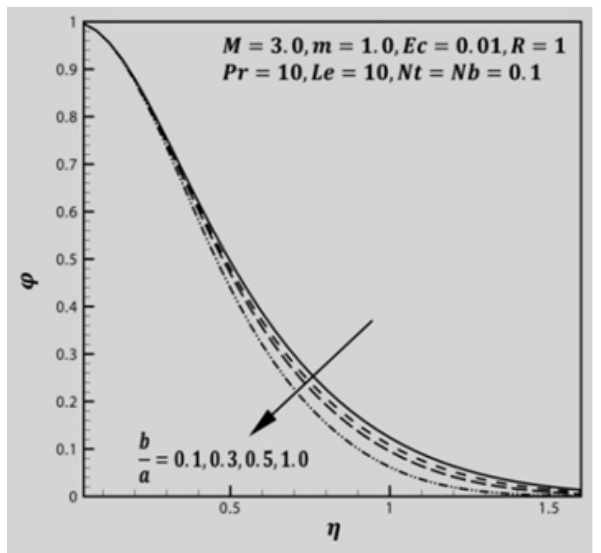

Figure 9: Effect of $b / a$ on concentration profiles

In figures 6 and 7 , the dimensionless temperature distribution $\theta(\eta)$ and the dimensionless concentration distribution $\varphi(\eta)$ are plotted respectively for the different values of Magnetic parameter $M$ where $N t=N b=0.1, \operatorname{Pr}=10, L e=$ $10, R=1.0, b / a=0.5, E c=0.01$ and $m=1.0$. It is observed that, as the magnetic parameter $M$ increases the temperature and concentration increases gradually.

In figures 8 and 9 , the dimensionless temperature distribution $\theta(\eta)$ and the dimensionless concentration distribution $\varphi(\eta)$ are described respectively for the different values of stretching parameter $b / a$ where $M=3.0, N t=N b=$ 


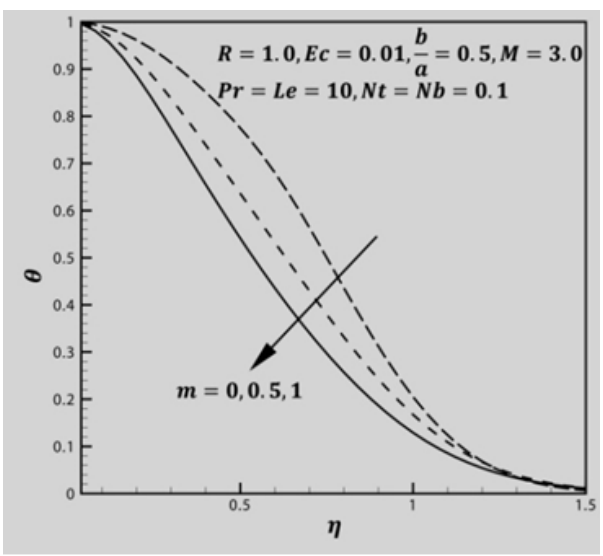

Figure 10: Effect of $m$ on temperature profiles

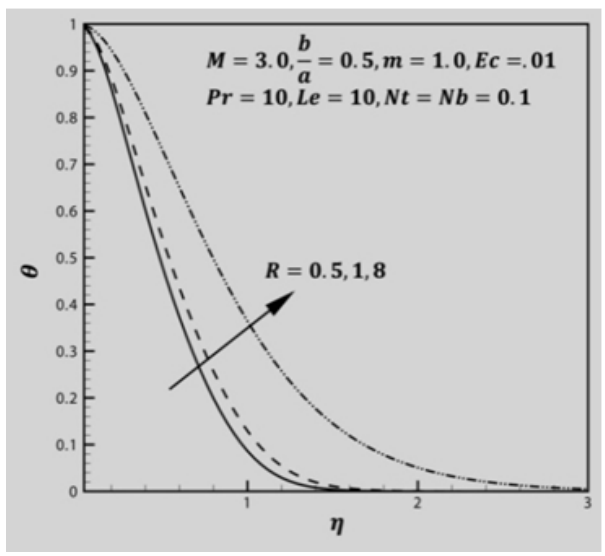

Figure 12: Effect of $R$ on temperature profiles

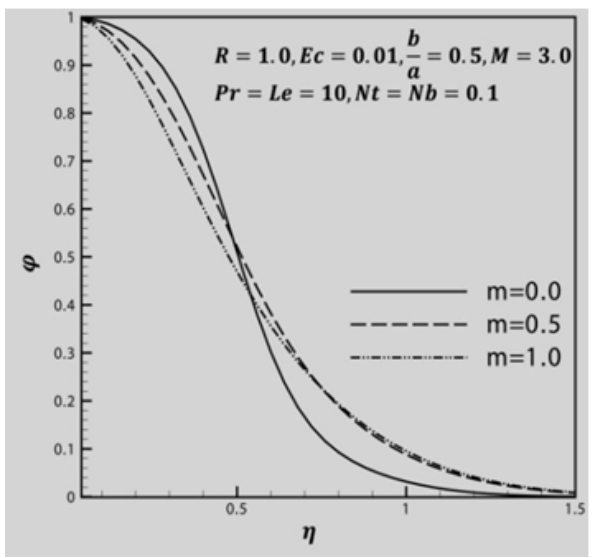

Figure 11: Effect of $m$ on concentration profiles

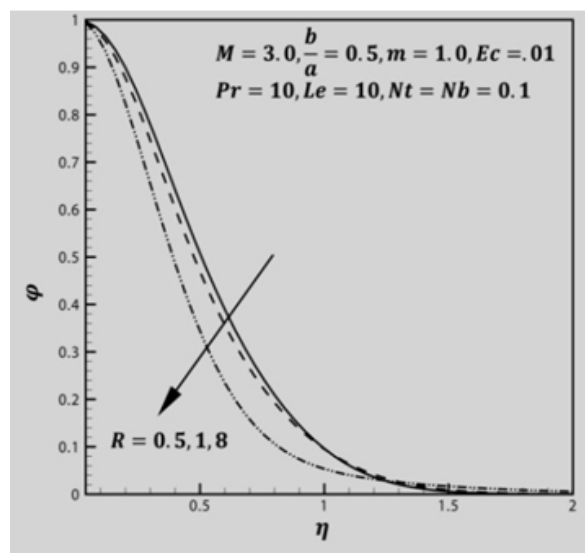

Figure 13: Effect of $R$ on concentration profiles

0.1, $\operatorname{Pr}=10, L e=10, R=1.0, E c=0.01$ and $m=1.0$. It is observed that, as the stretching parameter $b / a$ increases the temperature and concentration decreases.

In figures 10 and 11 the dimensionless temperature distribution $\theta(\eta)$ and the dimensionless concentration distribution $\varphi(\eta)$ are plotted respectively for the different values of constant parameter $m$ where $M=3.0, N t=N b=0.1$, $\operatorname{Pr}=10, L e=10, R=1.0, b / a=0.5$ and $E c=0.01$. It is observed that, as the constant parameter $m$ increases the temperature and concentration decreases gradually. 
In figures 12 and 13 the dimensionless temperature distribution $\theta(\eta)$ and the dimensionless concentration distribution $\varphi(\eta)$ are plotted respectively for the different values of Radiation parameter $R$ where $M=3.0, N t=N b=0.1, \operatorname{Pr}=$ $10, L e=10, b / a=0.5$ and $E c=0.01$. There is an increase in the Radiation parameter $R$ leads to an increase in the temperature while the reverse effects have been found for concentration.

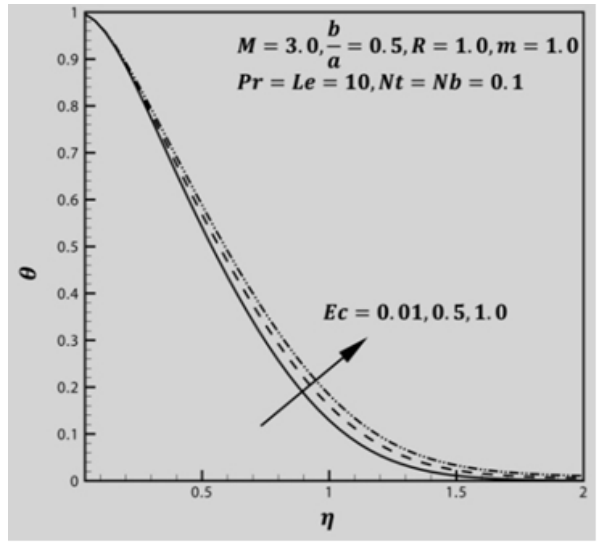

Figure 14: Effect of $E c$ on temperature profiles

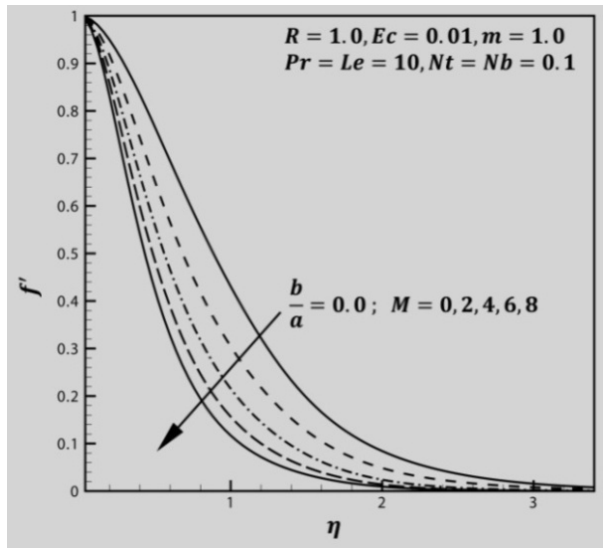

Figure 16: Effect of $M$ on velocity profiles when $b / a=0.0$

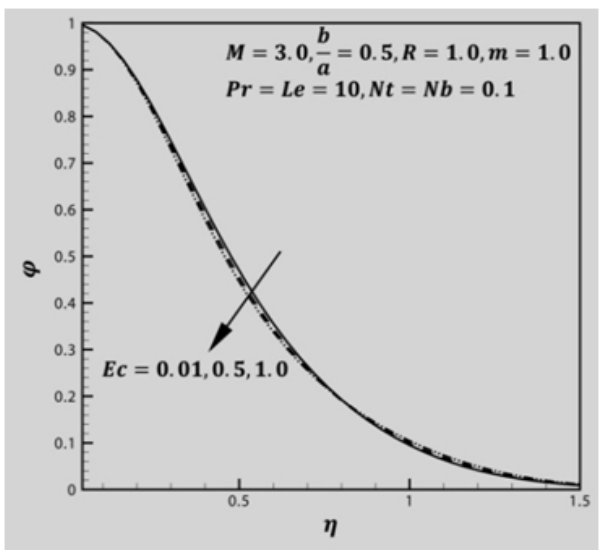

Figure 15: Effect of Ec on concentration profiles

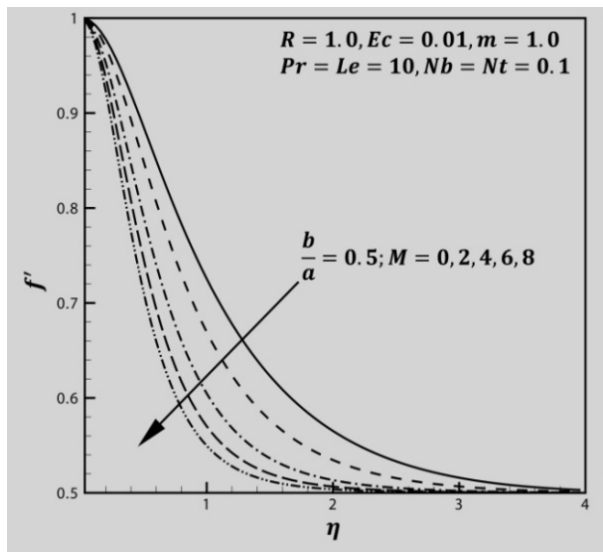

Figure 17: Effect of $M$ on velocity profiles when $b / a=0.5$

In figures 14 and 15 the dimensionless temperature distribution $\theta(\eta)$ and the dimensionless concentration distribution $\varphi(\eta)$ are plotted respectively for the different values of Eckert number $E c$ where $M=3.0, N t=N b=0.1, \operatorname{Pr}=$ 
$10, L e=10, m=1.0, R=1.0$ and $b / a=0.5$. It is noticed that, as increase in the $E c$ the temperature increases where as concentration decreases.

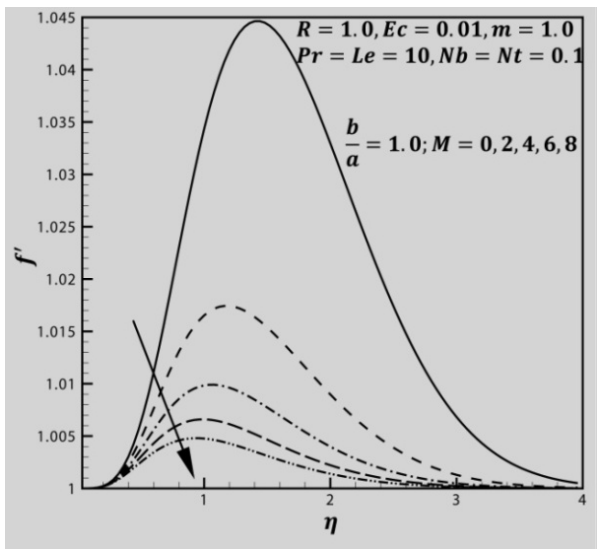

Figure 18: Effect of $M$ on velocity profiles when $b / a=1.0$

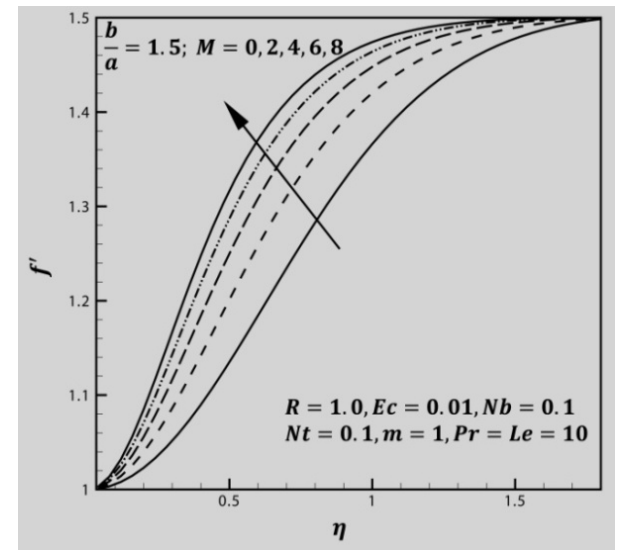

Figure 19: Effect of $M$ on velocity profiles when $b / a=1.5$

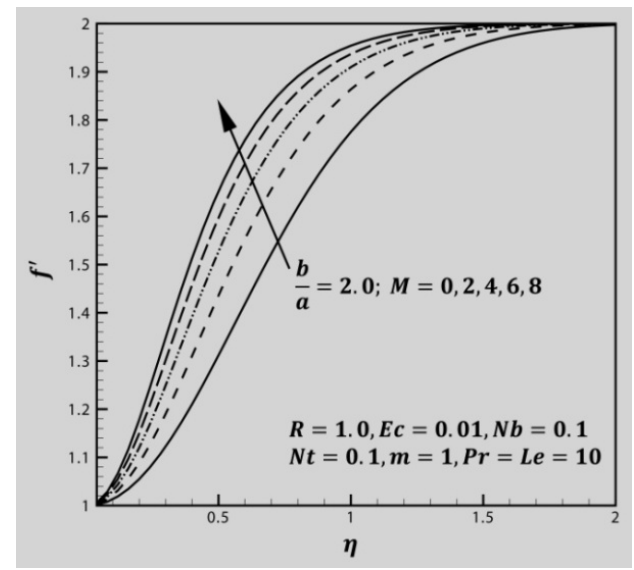

Figure 20: Effect of $M$ on velocity profiles when $b / a=2.0$

In figures 16-20 the dimensionless velocity distribution $f^{\prime}(\eta)$ plotted respectively for different values of Magnetic parameter $M$ where $N t=N b=0.1, \operatorname{Pr}=$ 10, $L e=10, m=1.0, E c$ and $R=1.0$. Consider here the values of stretching parameter $b / a=0,0.5,1.0,1.5$ and 2.0. It is observed that, as the Magnetic parameter $M$ increases the velocity decreases gradually when $b / a=0,0.5$ and 1 while the reverse effect have been found when $b / a=1.5$ and 2.0. And the velocity profiles are converges with respect to boundary conditions. 
Since the physical interest of the problem, the dimensionless skin-friction coefficient $\left(-f^{\prime \prime}\right)$, the dimensionless heat transfer rate $\left(-\theta^{\prime}\right)$ and the dimensionless mass transfer rate $\left(-\varphi^{\prime}\right)$ at the sheet are plotted against Thermophoresis parameter $N t$ and illustrated in figures 21-32.

Figure 21 shows the dimensionless heat transfer rate $\left(-\theta^{\prime}\right)$ plotted against Thermophoresis parameter $N t$ for the different values of Magnetic parameter $M$ where $N b=0.1, \operatorname{Pr}=10, L e=10, m=1.0, R=1.0$ and $b / a=0.5$. It is noted that there is an increase in heat transfer rate as Magnetic parameter $M$ increases.

Figure 22 displays the dimensionless heat transfer rate $\left(-\theta^{\prime}\right)$ plotted against Thermophoresis parameter $N t$ for the different values of Radiation parameter $R$ where $M=3.0, N b=0.1, \operatorname{Pr}=10, L e=10, m=1.0$ and $b / a=0.5$. It is observed that there is an increase in heat transfer rate as Radiation parameter $R$ increases.

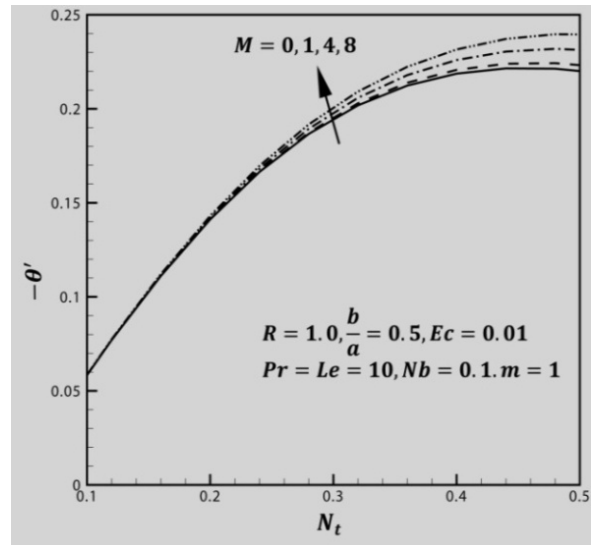

Figure 21: Effect of $M$ on heat transfer rate

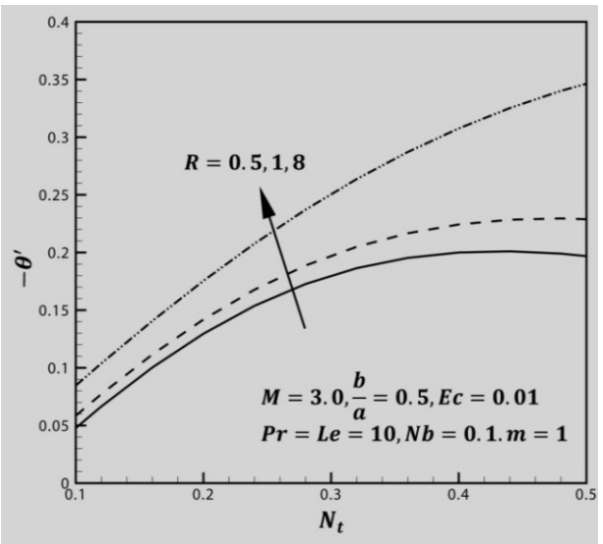

Figure 22: Effect of $R$ on heat transfer rate

Figure 23 represents the dimensionless heat transfer rate $\left(-\theta^{\prime}\right)$ plotted against Thermophoresis parameter $N t$ for the different values of stretching parameter $b / a$ where $M=3.0, N b=0.1, \operatorname{Pr}=10, E c=0.01, L e=10, m=1.0$ and $R=1.0$. It is examined that there is a decrease in heat transfer rate as Stretching parameter $b / a$ increases.

Figure 24 illustrates the dimensionless heat transfer rate $\left(-\theta^{\prime}\right)$ plotted against Thermophoresis parameter $N t$ for the different values of constant parameter $m$ where $M=3.0, N b=0.1, \operatorname{Pr}=10, L e=10, R=1.0, E c=0.01$ and $b / a=0.5$. It is detected that there is a decrease in heat transfer rate as constant parameter $m$ increases. 
Figure 25 portrays the dimensionless heat transfer rate $\left(-\theta^{\prime}\right)$ plotted against Thermophoresis parameter $N t$ for the different values of Eckert number $E c$ where $M=3.0, N b=0.1, \operatorname{Pr}=10, L e=10, m=1.0, R=1.0$ and $b / a=0.5$. It is verified that there is an increase in heat transfer rate as Eckert number Ec increases.

Figure 26 depicts the dimensionless mass transfer rate $\left(-\theta^{\prime}\right)$ plotted against Thermophoresis parameter $N t$ for the different values of Magnetic parameter $M$ where $N b=0.1, \operatorname{Pr}=10, L e=10, m=1.0, R=1.0, E c=0.01$ and $b / a=$ 0.5. It is noted that there is an increase in mass transfer rate as Magnetic parameter $M$ increases.

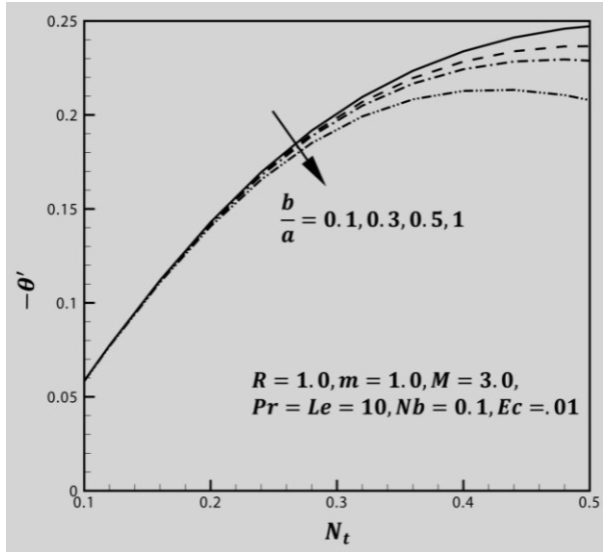

Figure 23: Effect of $b / a$ on heat transfer rate

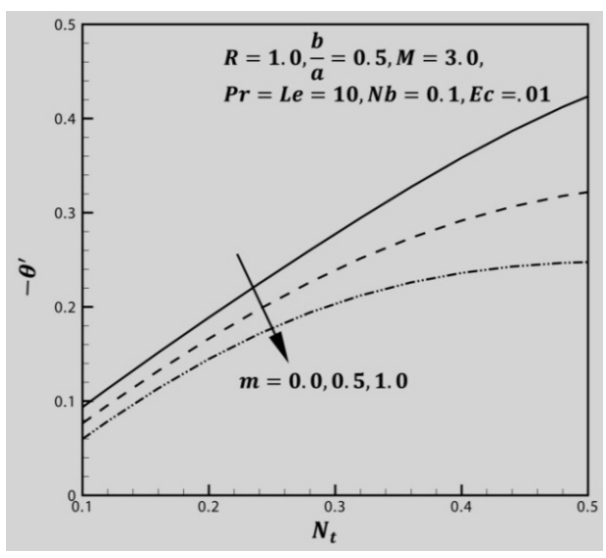

Figure 24: Effect of $m$ on heat transfer rate

Figure 27 exhibits the dimensionless mass transfer rate $\left(-\theta^{\prime}\right)$ plotted against Thermophoresis parameter $N t$ for the different values of Radiation parameter $R$ where $M=3.0, N b=0.1, \operatorname{Pr}=10, L e=10, m=1.0, E c=0.01$ and $b / a=$ 0.5. It is observed that there is a decrease in mass transfer rate as Radiation parameter $R$ increases.

Figure 28 displays the dimensionless mass transfer rate $\left(-\theta^{\prime}\right)$ plotted against Thermophoresis parameter $N t$ for the different values of stretching parameter $b / a$ where $M=3.0, N b=0.1, \operatorname{Pr}=10, L e=10, m=1.0, R=1.0$ and $E c=$ 0.01 . It is examined that there is a decrease in mass transfer rate as stretching parameter $b / a$ increases.

Figure 29 represents the dimensionless mass transfer rate $\left(-\theta^{\prime}\right)$ plotted against Thermophoresis parameter $N t$ for the different values of constant parameter where $M=3.0, N b=0.1, P r=10, L e=10, m=1.0, R=1.0$ 


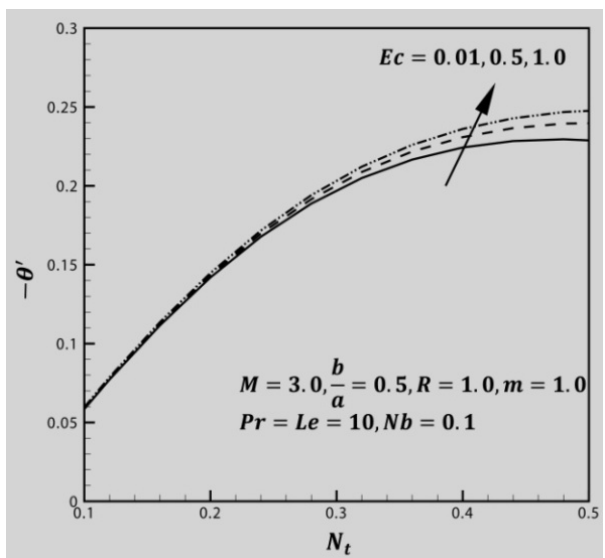

Figure 25: Effect of Ec on heat transfer rate

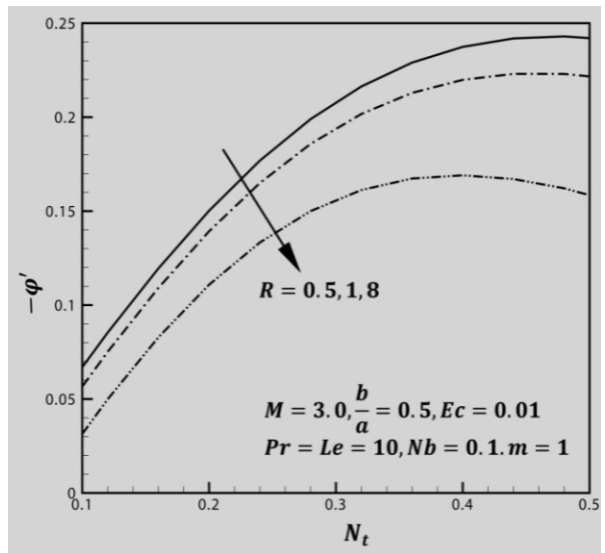

Figure 27: Effect of $R$ on mass transfer rate

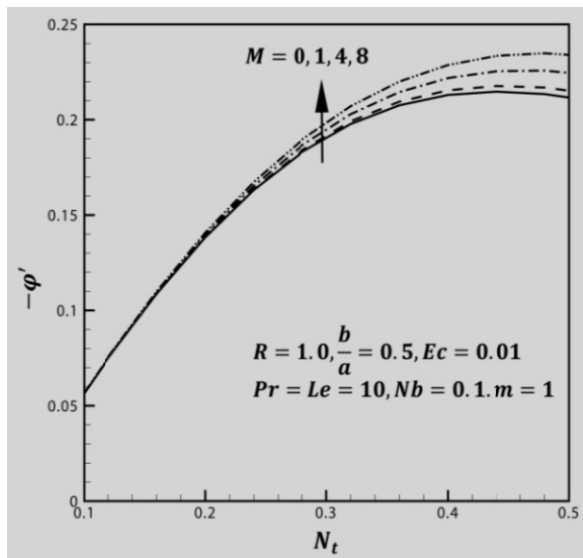

Figure 26: Effect of $M$ on mass transfer rate

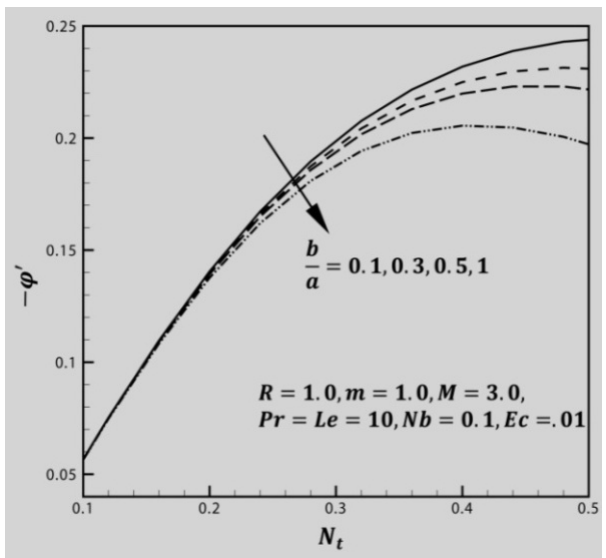

Figure 28: Effect of $b / a$ on mass transfer rate

and $b / a=0.5$. It is detected that there is a decrease in mass transfer rate as constant parameter $m$ increases.

Figure 30 shows the dimensionless mass transfer rate $\left(-\theta^{\prime}\right)$ plotted against Thermophoresis parameter $N t$ for the different values of Eckert number $E c$ where $M=3.0, N b=0.1, \operatorname{Pr}=10, L e=10, m=1.0, R=1.0$ and $b / a=0.5$. It is verified that there is a decrease in mass transfer rate as Eckert number $E c$ increases.

Figure 31 illustrates the dimensionless skin-friction coefficient $\left(-f^{\prime \prime}\right)$ plotted against Thermophoresis parameter $N t$ for the different values of Magnetic 


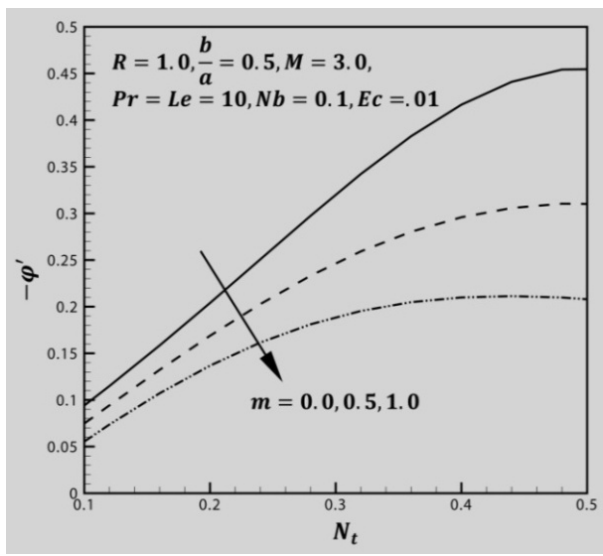

Figure 29: Effect of $m$ on mass transfer rate

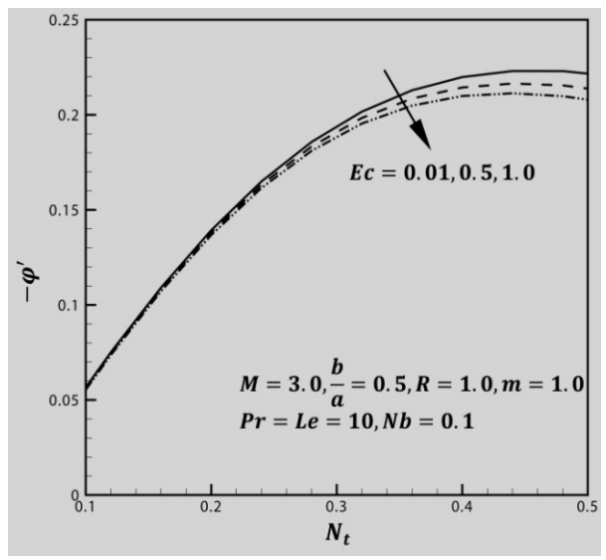

Figure 30: Effect of Ec on mass transfer rate

parameter $M$ where $N b=0.1, \operatorname{Pr}=10, L e=10, m=1.0, R=1.0, E c=0.01$, and $b / a=0.5$. It is verified that there is an increase in skin-friction coefficient as Magnetic parameter $M$ increases.

Figure 32 shows the dimensionless skin-friction coefficient $\left(-f^{\prime \prime}\right)$ plotted against Thermophoresis parameter $N t$ for the different values of stretching parameter $b / a$ where $M=3.0, N b=0.1, \operatorname{Pr}=10, L e=10, m=1.0, R=1.0$ and $E c=0.01$. It is verified that there is an increase in skin-friction coefficient as stretching parameter $b / a$ increases.

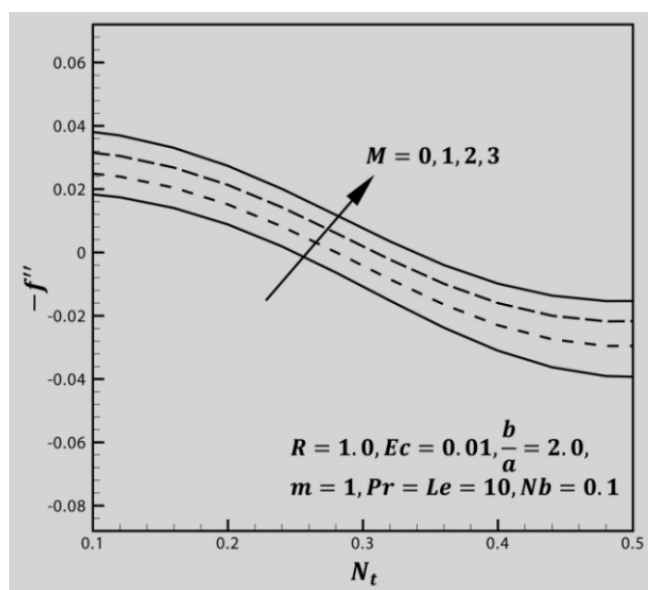

Figure 31: Effect of $M$ on skin-friction coefficient

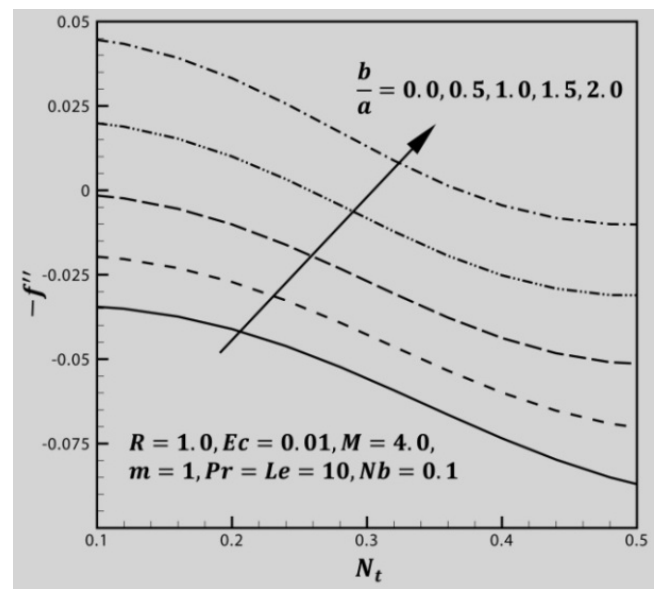

Figure 32: Effect of $b / a$ on skin-friction coefficient 


\section{Conclusions}

Laminar boundary layer flow of a nanofluid has been investigated for steady flow over the stretching surface with the influence of magnetic field and thermal radiation. The effects of Brownian motion and thermophoresis are incorporated into the model for nanofluids. The results are presented for various parameters. The velocity, temperature and concentration distributions also dimensionless skin-friction coefficient, heat and mass transfer rates at the sheet for different parameters are studied and shown graphically. We anticipate that our model would be useful to develop newer applications of magnetic fluids and magnetic flow. For the accuracy of the numerical results, a comparison with Khan and Pop [20] has been showed. The important findings of the investigation from graphical representation are listed below:

- The temperature and concentration boundary layer thickness increases as the magnetic parameter increases for nanofluids. Also the surface heat and mass transfer rate at the sheet are increased. It is interesting to note that the impacts of thermophoresis particle deposition in the presence of magnetic field with Brownian motion have a substantial effect on the flow field and, thus, on the skin-friction coefficient, heat transfer and concentration rate from the sheet to the fluid. Nanofluids are important because they can be used in numerous applications involving heat transfer and other applications such as in science and technology of magnetic fluids.

- As the Stretching parameter increases the temperature and concentration boundary layer thickness decreases gradually for nanofluids. There is also decrease in heat and mass transfer rate at the sheet have been found.

- The temperature and concentration boundary layer thickness decreases gradually as the constant parameter increases for nanofluids. Also the heat transfer rate and mass transfer rate at the sheet are decreased.

- As the Radiation parameter increases the temperature increases while the reverse effect have been found for concentration boundary layer thickness for nanofluids. There is an increase in heat transfer rate and decrease in mass transfer rate have also found.

- As the Eckert number increases the temperature boundary layer thickness increases for nanofluids while the reverse effect have been found for 
concentration boundary layer thickness. Also an increase in heat transfer rate at the sheet and decrease in mass transfer rate at the sheet have been found.

- The velocity profiles decreases for increasing Magnetic Parameter when the values of Stretching parameter is up to 1.0, but when the Stretching parameter take values $>1$ (up to 2.0) then the velocity profiles increases. Also the skin-friction coefficient increases for increasing Magnetic Parameter as well as stretching parameter.

\section{References}

[1] S. U. S. Choi, Enhancing thermal conductivity of fluids with nanoparticles, In: D.A. Siginer, H.P. Wang (Eds.), Developments and Applications of Non-Newtonian Flows, ASME FED, 231/MD- 66 (1995), 99-105.

[2] Pooya M. Rad, C. Aghanajafi, The Effect of Thermal Radiation on Nanofluid Cooled Microchannels, J. Fusion Energ., 28 (2009), 91-100.

[3] A. A. Afify, M. A. Seddeek, M. A. A. Bbazid, Radiation effects on FalknerSkan flow of a nanofluid past a wedge in the present of non-uniform heat source/ sink, Meccanica, 2011, Submitted.

[4] K. Vajravelu, A. Hadjinicolaou, Convective heat transfer in an electrically conducting fluid at a stretching surface with uniform free stream, Int. J. Eng. Sci., 35 (1997), 1237-1244.

[5] I. Pop, T. Y. Na, A note on MHD flow over a stretching permeable surface, Mech. Res. Comm., 25 (1998), 263-269.

[6] H. S. Takhar, A. J. Chamkha, G. Nath, Flow and heat transfer on a stretching surface in a rotating fluid with a magnetic field, Int. J. Therm. Sci., 42 (2003), 413-422.

[7] A. J. Chamkha, MHD flow of a uniformly stretched vertical permeable surface in the presence of heat generation/absorption and a chemical reaction, Int. Comm. Heat Mass Trans., 30 (2003), 413-422.

[8] P. Singh, A. Jangid, N. S. Tomer, D. Sinha, Effects of thermal radiation and magnetic field on unsteady stretching permeable sheet in presence of free stream velocity, Intl. J. Info. Math. Sci., 6:3 (2010). 
[9] M. Ferdows, Ota, M. A. Sattar, M. M. Alam, Similarity Solution for MHD Flow through a Vertical Porous Plate with Suction, J. Comp. Appl. Mech., 6:1 (2005), 15-25.

[10] A. A. Afify, Nasser S. Elgazer, Lie group analysis for the effects of chemical reaction on MHD stagnation-point flow of heat and mass transfer towards a heated porous stretching sheet with suction or injection, Nonlinear Analysis: Modelling and Control, (Accepted).

[11] A. A. Afify, Some new exact solutions for MHD aligned creeping flow and heat transfer in second grade fluids by using Lie group analysis, Nonlinear Anal. Theor. Meth. Appl., 70 (2009), 3298-3306.

[12] M. Turkyilmazoglu, Multiple solutions of heat and mass transfer of MHD slip for the viscoelastic fluid over a stretching sheet, Intl. J. Thermal Sci., 50 (2011), 2264-2276.

[13] H. Masuda, A. Ebata, K. Teramae, N. Hishinuma, Alteration of thermal conductivity and viscosity of liquid by dispersing ultra-fine particles, Netsu Bussei, 7 (1993), 227-233.

[14] J. Buongiorno, W. Hu, Nanofluid coolants for advanced nuclear power plants, Paper no. 5705, Proceedings of ICAPP '05, Seoul, South Korea, May (2005) 15-19.

[15] W. Yu, D. M. France, J. L. Routbort, S. U. S. Choi, Review and comparison of nanofluid thermal conductivity and heat transfer enhancements, Heat Transf Eng., 29 (2008), 432-460.

[16] S. M. S. Murshed, K. C. Leong, C. Yang, Thermophysical and electrokinetic properties of nanofluids - a critical review, Appl. Therm. Eng., 28 (17-18), (2008), 2109-2125.

[17] S. P. Jang, S. U. S. Cho, Effects of Various Parameters on Nanofluid Thermal Conductivity, J. Heat Transfer, 129 (2007), 617-623.

[18] A. V. Kuznetsov, D. A. Nield, Natural convective boundary-layer flow of a nanofluid past a vertical plate, Int. J. Thermal Sci., 49 (2010), 243-247.

[19] D. A. Nield, A. V. Kuznetsov, The Cheng-Minkowycz problem for natural convective boundary layer flow in a porous medium saturated by a nanofluid, Int. J. Heat Mass Transfer, 52 (2009), 5792-5795. 
[20] W. A. Khan, I. Pop, Boundary-Layer Flow of a Nanofluid Past a Stretching Sheet, Intl J. Heat Mass Transfer, 53 (2010), 2477-2483.

[21] M. Hassani, M. M. Tabar , H. Nemati, G. Domairry, F. Noori, An analytical solution for boundary layer flow of a nanofluid past a stretching sheet, Intl J. Thermal Sci, 50 (2011), 2256-2263.

[22] A. A. Avramenko, D. G. Blinov, I. V. Shevchuk, Self-similar analysis of fluid flow and heat-mass transfer of nanofluids in boundary layer, Phy. Fluids, 23 (2011), 082002.

[23] N. Bachok, A. Ishak, I. Pop, Boundary-layer flow of nanofluids over a moving surface in a flowing fluid, Intl. J. Thermal Sci., 49:9 (2010), $1663-1668$.

[24] N. Yacob, A. Ishak, I. Pop, K. Vajravelu, Boundary layer flow past a stretching/ shrinking surface beneath an external uniform shear flow with a convective surface boundary condition in a nanofluid, Nanoscale Research Letters, 6:314 (2011), content/6/1/314.

[25] M. A. A. Hamad, M. Ferdows, Similarity solution of boundary layer stagnation- point flow towards a heated porous stretching sheet saturated with a nanofluid with heat absorption/generation and suction/blowing: A lie group analysis, Comm. Nonlinear Sci. Numer. Simula., (2011), (Accepted).

[26] M. A. A. Hamad, M. Ferdows, On Similarity solution to the viscous flow of heat transfer of nanofluid over nonlinearly stretching sheet, Math. Model. Anal., Manuscript ID: TMMA- (2011), 0104, (Accepted).

[27] M. A. A. Hamad, Analytical solution of natural convection flow of a nanofluid over a linearly stretching sheet in the presence of magnetic field, Intl. Comm. Heat Mass Transfer, 38 (2011), 487-492.

[28] S. M. Aminossadati, A. Raisi, B. Ghasemi, Effects of magnetic field on nanofluid forced convection in a partially heated microchannel, Internat. J. Non-Linear Mech., 46 (2011), 1373-1382.

[29] M. A. A. Hamad, I. Pop, Unsteady MHD free convection flow past a vertical permeable flat plate in a rotating frame of reference with constant heat source in a nanofluid, Heat Mass Transfer, 47 (2011), 1517-1524. 
[30] M. Q. Brewster, Thermal Radiative Transfer and Properties, John Wiley and Sons Inc, New York, USA, 1992.

[31] P. R. Nachtsheim, P. Swigert, Satisfaction of the asymptotic boundary conditions in numerical solution of the system of non-linear equations of boundary layer type, NASA, TND-3004, (1995).

Received: October 21, 2015 